\title{
In praise of promoting prisms of praise
}

\author{
George M Jacobs \\ Kampung Senang Charity and Education Foundation \\ george.jacobs@gmail.com \\ Stephen J Hall \\ Sunway University \\ stephenh@sunway.edu.my
}

\begin{abstract}
Advice for teachers often includes advice on the quality and quantity of the praise they give students. The present article reviews and perhaps adds to that advice, as well as cautioning that the influence of culture needs to be borne in mind when praise is considered. The two theories discussed in the introductory part of this article, Behaviorism and Social Constructionism, provide different but not necessarily incompatible advice on praise. The article's twelve specific suggestions on praise may be a useful review or new ideas. Included among those suggestions are ideas for involving people other than teachers in praising students, to praise not just the result but also the process used towards that result and those who helped in the process, and in giving praise, to highlight the class's long-term goals. Certainly, the suggestions are relevant not only for teachers but also for other stakeholders in Education and beyond.
\end{abstract}

Keywords: praise, behaviorism, social constructionism, positive psychology, ipsative assessment, 360-degree assessment 


\section{Introduction}

Praise has been a key topic in Education for decades. Teachers and others use praise as a tool for giving feedback to students, encouraging them to be engaged in academic and co-curricular activities, and maintaining a conducive classroom environment. This article begins by looking at praise from the perspectives of two prominent theories on behavior and learning: Behaviorism, which was dominant among academics and in classrooms, and may still be dominant in classrooms, and Social Constructionism, which is now dominant among academics and may slowly be gaining ascendancy in classrooms, as well as online learning.

\section{Theoretical Perspectives on Praise}

For many years, Behaviorism, particularly in the form of Operant Conditioning (Skinner, 1953), was a dominant perspective in both academia and in teaching and classroom management. According to Operant Conditioning, behaviors are more or less likely to be repeated based on the responses to those behaviors. If behaviors are rewarded, e.g., by praise or by material rewards, such as food or money, those behaviors are strengthened, i.e., they are more likely to be repeated by humans and other organisms. Conversely, when behaviors are not praised or otherwise rewarded or even are punished, i.e., the goals of the organisms who did the behaviors (Behaviorism's laws of learning apply to human and nonhuman animals) are not achieved, the behaviors are weakened, i.e., they become less likely to reoccur.

In this teacher-centered view of praise and Education generally, extrinsic motivation (Ryan \& Deci, 2020) is teachers' main instrument to promote student engagement. When students give correct answers, praise is a prime way that teachers positively reinforce this behavior and, thus, make it likely that students would give the same correct response in the future. Furthermore, according to Bandura, Ross, and Ross (1963), in addition to directly reinforcing students for their individual correct behaviors, vicarious reinforcement could also be used, i.e., by publicly praising one or more students, those students who had not been praised themselves but had witnessed others being praised could also be encouraged to perform similar correct behaviors. Advocates of cooperative learning, e.g., Slavin (1995), highlight that in addition to teachers, peers could also provide each other with positive reinforcement. 


\subsection{Social Constructionism}

In approximately the last quarter of the $20^{\text {th }}$ century, the dominance of Behaviorism declined, as a new paradigm started to rise in its place (Jacobs \& Farrell, 2001). This paradigm has different names; however, in this paper, it will be called Social Constructionism. As the name implies, this view sees each person constructing their own knowledge in concert with the people with whom they interact and cultures in which they live. Roots of Social Constructionism can be traced to such theorists as Bruner (1966), Dewey (1910), Piaget and Inhelder (1962), and Vygotsky (1978). Social Constructionism supports an emphasis on student-centered learning (Jacobs, Renandya, \& Power, 2016) and intrinsic motivation (Kohn, 1999; Ryan \& Deci, 2020).

Praise still receives attention in Social Constructionism, except instead of praise being a tool for utilizing teacher-centered extrinsic motivation as in Behaviorism, praise becomes information, from a cognitive (ideas and information) perspective, and encouragement and bonding, from an affective (feelings) perspective (Carr \& Boat, 2019). For instance, Holmes (1986) described a compliment as a strategy to make others feel good about themselves, noting that, "The primary function of a compliment is most obviously affective and social" (p. 485). Thus, praise done well can guide and inspire students as they interact with others to consciously construct their own understanding of the world and decide how to deploy that understanding.

\subsection{Neuroscience}

Following after and supporting Social Constructionism have been major developments in neuroscience (Coch, 2018). Behaviorism developed before these developments in neuroscience, and the name Behaviorism comes from the theory's emphasis on observable behavior, as at the time that Behaviorism was developed, scientists did not yet have the tools that would later enable neuroscientists to look inside the minds of humans and other animals. However, even before the rise of neuroscience, dissatisfaction with Behaviorism was growing, as often occurs before a paradigm shift in any field (Kuhn, 1962). Social Constructivism arose by learning from as well as opposing the ideas of the Behaviorists (Gardner, 1987).

Although lacking the concrete evidence that neuroscience would later provide about how minds work, some psychologists speculated on what happens inside our minds as we think (Witt, Linkenauger, \& Wickens, 2016), developing, for instance, the Information Processing Model of learning and recall (Baddeley \& Hitch, 1974). However, behaviorists rejected such speculation as 
unscientific. Now, we do not need to speculate; the tools of neuroscience enable us to see much of what occurs as we think, and these observations confirm much of what social constructionists had previously speculated (Armstrong, 2016; Willis, 2007).

\section{Cultural Dimensions of Giving and Accepting Praise}

Social constructionists recognise that while the basic physiology including the nervous system of all humans, is the same worldwide, important variations do exist in how humans interact. Culture plays a role in these variations, and praise is one area in which cultural differences manifest themselves (Pomerantz, 1978). For example, Golato (2005) observed that in some cultures, receivers of praise are under pressure to deflect or downplay praise in order to appear modest. Additionally, Hofstede (2011), in his famous work on the role of culture, noted the impact of perceived power distance on interpersonal interactions.

Another instance of the role of culture can be seen in findings that while acceptance of compliments is the norm in American discourse (Wolfson, 1981), complication arises because praise may have become a regular speech act, such as a greeting, rather than a genuine response to a meritorious act. Yet another example, this time in Japanese culture, is found in the work of Ishiara (2003) who reported that given the value of modesty in Japanese discourse, generalised praise may not be perceived as genuine and that acceptance may depend on perceptions of the purposes of the praise and the genuineness of what is being said.

Malaysia presents more examples of the potentially complicated nature of praise. In older generations of Malaysians, giving and accepting compliments are not a common occurrence in everyday interactions, plurilingual or in one's first language (Lee, 2007). In Malay culture, the norm is to neutralize praise or to say something contradictory about an aspect of praise (Asmah Haji Omar, 1992), because accepting or agreeing with a compliment would portray the recipient as an arrogant person. This often means praise engenders phrases such as, "Oh, it is nothing really" or "It was all the team's work." Indirectness in interaction is a norm as indirect praise is used to protect one's face and show respect to others (Azianuri Hani Shaari \& Marlina, 2017).

Through social networking, cultural globalization has, however, brought about changes in giving and receiving praise in Malaysia. Azianura Hani Shaari and Lee (2010) and Azianura Hani Shaari and Marlyan (2017) found that the younger generation of digitally literate Malays appreciated and gave compliments, and that code switching enhanced the giving and acceptance 
of compliments a finding. Perhaps those who are multilingual could consider how code-switching or plurilingualism may impact their giving of praise and their reactions to being praised (Hall, 2018). Clearly being sensitive to language choices, attributing to the group or acknowledging a simple "thank you" in the listener's choice of language, play an important part in effective crosscultural praising.

\section{General Guidance of Praising}

Finley (2016) summarized much of the general wisdom in Education on giving praise. Before reviewing that, it bears emphasizing that implementation of these guidelines, and most advice in Education, will seldom be a matter of one size fits all, as suggested in the above discussion on the role of culture. Instead, contexts and individuals differ according to a range of variables, including students' ages, personalities, cultural backgrounds, self-concepts, and previous experiences in education, e.g., some students may be uncomfortable with public praise, whereas others may be invigorated by it.

\subsection{Sincerity and Deservedness}

Students need to believe that the praise they receive is given sincerely and that they have earned the praise. In contrast, if students believe they are not deserving of the compliments they receive, the impact on their self-concept may be negative rather than positive, e.g., if students who are intermediate level writers are praised for beginning sentences with uppercase letters, they may think, "The teacher believes I'm not good; that's why I'm being praised for such a nothing act."

\subsection{Specificity}

Praise should be specific and informative. If teachers say to students, "Good job" or "Well done," students may not know what the teachers think the students did well. Also, as in vicarious reinforcement, other students who hear/see this praise may not be able to learn from it. Another term for specific praise is evidence-based praise, i.e., stating exactly what the student did, e.g., "Aisha, you invited Xavier to give their suggestions. Thus, you promoted equal opportunity to participate among everyone in the group." 


\subsection{Process-orientation}

Praise should focus on how students go about/went about tasks, rather than focusing solely on the result they produced. Immediate success is wonderful, but more often students achieve only approximations of success or success in some areas not others. Indeed, sometimes students fail. Examples abound in science and other areas of endeavor of repeated failures that only became successes after people learned from trying repeatedly. In this vein, the teaching of resilience (Dweck \& Yeager, 2019) and of learning strategies (Neroni et al., 2019) feature prominently on many schools' agendas, with the idea that these habits of mind prepare students to focus more on process than on product, thus enabling them to equip themselves for lifelong learning.

Including questions in praise provides one way to include process in praise (Averill et al., 2016). After students receive praise, questions can prompt them to reflect on how they did what they were praised for, e.g., when students are praised for giving reasons to support their ideas, an appropriate follow-up question might be, "Why do you use reasons to back up what you say?" or "How did you find the reasons you used?" Such questions encourage reflection among the students being asked as well as among those who are listening.

\subsection{Frequency}

Students benefit both cognitively and affectively from frequent feedback. This is one of the reasons that many educators favor an increased emphasis on formative assessment, rather than summative assessment (Torres, 2019), as formative assessment occurs much more frequently than does summative assessment, i.e., while formative assessment can take place multiple times in one lesson, summative assessment may manifest as seldom as once a year. Sincere, specific, processcentered praise given multiple times in a lesson can guide and inspire students as they go about their learning activities.

\subsection{Gratitude}

Another way to provide praise can be to express gratitude. The literature on Positive Psychology highlights the many benefits enjoyed both by those who receive messages of gratitude, as well as by those who give them (Seligman, 2011). For example, teachers can say to students, "I'm grateful that you continued to try even though you had problems. I'm going to remember that the next time I have problems with a task in my own life." This form of praise can also be valuable, because it 
reverses roles, with students teaching their teachers, instead of students always being on the receiving end of instruction.

\subsection{Surprise}

Praise should not be routine. An example of routine praise would be that at the end of lessons, teachers say, "Okay. Good job everyone. You really crushed it today." This is similar to the problem noted above with praise in the U.S. which may seem more like an everyday speech act than an unique occurrence. Such ordinary praise is not only not specific, but it also seems automatic and, therefore, perhaps not deserved. When, in contrast, praise comes when not expected, it may seem more sincere. Piaget (1977) proposed that surprise caused people to reorganize their thinking. He labelled this process "accommodation."

\subsection{Criteria}

The assessment used for giving praise can be divided into three types: norm-referenced, criterionreferenced, and ipsative (Jacobs \& Greliche. 2017). Norm-referenced assessment compares students to each other. Thus, the criteria used are the performances of the other students doing the same assessment. In terms of praise, this type of assessment can be likened to what Achor (2018) called comparison praise, i.e., telling people they are the best anything, e.g., the best student in a class. Achor advised that comparison praise is uninformative, because it does not tell people how good they are; it only tells them they are better than some others, e.g., being the best student in a class of low proficiency students is faint praise. Also, comparison praise discourages sharing, as it makes some people feel good by making others feel bad. Comparison praise is comparison, not praise.

Instead of praising students based on comparison with peers, praise can be based on criteria-referenced assessment, i.e., students can be praised based on their performance relative to a standard or criterion. In this way, everyone can earn praise - everyone can be a winner especially when students appreciate that they can learn by helping peers. At the same time, those giving criterion-referenced praise need to bear in mind, as stated in \#3 above, the value of a process orientation. 


\subsection{Past performance}

The third type of assessment, ipsative, bases praise on the individual's past performances as the criteria, i.e., instead of comparing people with others (norm-referenced) or with standards (criterion-referenced), ipsative assessment compares students and others only with themselves, and that comparison can involve not only their results but also their processes. Ipsative assessment, like criteria-referenced assessment, does not pit students against each other; instead, by learning with each other, students can learn more and thereby boost their performance by ipsative measurement.

\section{Praise from and to Everyone}

One form of evaluation bears the name 360-degree appraisal (Cheng \& Wu, 2020). Traditionally, people are assessed only by those above them in the organizational hierarchy, e.g., in Education, principals assessing teachers and teachers assessing students. The 360 degrees means that people are assessed by those above, below, and at the same level of the organizational hierarchy, not to mention self assessment. The present article highlights peer assessment, but while including 360degree assessment from many sources. Benefits of 360 degree praise include greatly increasing the number of people available to do assessment; making it easier for people to internalize assessment criteria because they practice the criteria as they deploy them and which they can have a role in developing, and providing more insight into people's performance, especially when group activities take place, because often teachers are unable to simultaneously observe what all their students are doing (Elizondo-Garcia \& Gallardo, 2020).

Achor has worked for many years in positive psychology, an approach to well-being which emphasizes people's happy moments, their interests, their supportive relationships, what has meaning for them, their strengths, and their successes, and seeks to use these to overcome the negatives in their lives and their weaknesses (Achor, 2011a; 2011b; Seligman, 2011). However, positive psychology often focused on an individual perspective. For instance, Achor (2011a) made research-based recommendations for daily actions that would allow people to do what he called "rewire" their brains to have a happier outlook. These daily actions included people journaling about three people, places, objects, etc. that they are grateful for and about one positive event in their lives in the past 24 hours; thanking or praising someone; doing at least a bit of exercise; quieting their mind for at least two minutes; and performing a random act of kindness. 
As Achor and colleagues continued their research, they began to see this individual approach as self-limiting in that via this approach, individuals could only achieve their "small potential" (2018). Instead, Achor and his fellow researchers came to believe that a more social perspective would enable people to achieve "big potential." Everything they recommended previously remains useful, but they added strategies to widen their approach to enhancing wellbeing. This section of the present article shares strategies for using praise to seek this larger potential.

\subsection{Create Prisms of Praise}

Prisms are many-sided objects that refract light in different directions. The analogy with praise means that when we praise others, those we praise are more likely to praise others and us, thereby creating a more positive overall atmosphere, with praise emanating from more sources and nourishing more recipients. Thus, teachers can begin by praising students and others, being careful to give specific praise. Furthermore, teachers can teach the collaborative skill of praising others, and when teachers witness students praising others, this can be highlighted. The subsequent strategies in this article are all designed to operationalize these prisms of praise.

\subsection{Praise Everyone}

Achievements are seldom individual, i.e., no one succeeds alone, not even the famous people in the history books, such as Thomas Edison or Mohandas Gandhi. Yet, so often, it is only one person up on the stage with the award in their hand, with the promotion, with the full scholarship to university. To achieve big potential, while being accurate and specific, we should look to praise everyone who contributes to achievements. For instance, when students finish an assignment, such as a report, they can acknowledge those who helped them, including classmates and family members, as well as people in YouTube videos and social media.

\subsection{Democratize Praise}

Prisms have multiple surfaces, and the metaphor of prisms of praise means that praise can come from and be given to multiple people, not only those higher up in hierarchies. No matter what someone's ranking among those in a large or small group, everyone can and should be a praise leader. For example, people learn by teaching others, as long as explanations are included in the 
teaching (Webb et al., 2009). Therefore, even lower achieving groupmates can be praised for seeking help from their higher achieving peers and for asking for elaborated help, e.g., examples and applications.

Technology supplies many tools to democratize both the giving and receiving of praise; anyone with a smartphone can contribute praise, as long as they have opportunities. The chat function in Zoom offers yet another mode for communicating praise. Indeed, Achor (2018) cited data suggesting that $31 \%$ of people with positive feelings do not express them. This might occur for various reasons: lack of appreciation of the role their praise can play, concern about the safety of praising others, and shortage of knowledge about how to praise.

\subsection{Remember the Meaning}

People think deeper, try harder, and are more cohesive when they see and believe in what they are doing (Frankl, 1959). Praise needs to be linked to the purpose the group is striving to achieve. How does what is being praised move the group closer to achieving its purpose? For example, if a group has taken on a project to list all the eateries in a two kilometre radius of the school that offer plantbased options, the meaning driving their project could derive from the fact that plant-based food can be healthier, more environmentally friendly, and kinder to non-human animals (Hopwood et al., 2020).

Achor (2018) labeled this strategy an elevated pitch. Elevator pitches are short speeches used to promote an idea/business. In contrast, the strategy of elevated pitches calls on everyone, no matter their place in the hierarchy, to inspire each other to enable groups to attain their big potential. A related strategy uses praise each time progress is made toward common goals, because everyone contributed to that progress; thus, everyone has cause to celebrate and be celebrated.

\section{Conclusion}

This article revisited praise, a familiar topic in Education. The article began by discussing the perspectives on praise of two leading theories in Education: Behaviorism and Social Constructionism. Next to be discussed was the impact of humanity's many different cultures on how people give and receive praise. Then, the article presented some well-established but not always implemented guidance on praise including that praise should usually be specific and process oriented. The final and most unique area of the article reported ideas on how to involve 
more people in giving and receiving praise. The hope is that the prisms of praise that teachers, students, and others create can make education and life generally more productive, cooperative, and enjoyable.

\section{References}

Achor, S. (2011a). The happiness advantage: The seven principles of positive psychology that fuel success and performance at work. Random House.

Achor, S. (2011b, May). The happy secret to better work [Video file]. Retrieved from https://www.ted.com/talks/shawn_achor_the_happy_secret_to_better_work

Achor, S. (2018). Big potential: How transforming the pursuit of success raises our achievement, happiness, and well-being. Currency.

Armstrong, T. (2016). The power of the adolescent brain: Strategies for teaching middle and high school students. Association for Supervision and Curriculum Development.

Asmah Haji Omar. 1992. The linguistic scenery in Malaysia. Dewan Bahasa dan Pustaka, Ministry of Education, Kuala Lumpur, Malaysia.

Averill, R., Drake, M., Anderson, D., \& Anthony, G. (2016). The use of questions within in-themoment coaching in initial mathematics teacher education: enhancing participation, reflection, and co-construction in rehearsals of practice. Asia-Pacific Journal of Teacher Education, 44(5), 486-503.

Azianura Hani Shaari \& Lee, S. K. (2010). Traditional vs. modern values: Investigating compliments and compliment responses amongst the Malays. Journal of the Worldwide Forum on Education and Culture, 2(1) 1949-2774.

http://www.theworldwideforum.org/resources/journal2.pdf

Azianura Hani Shaari \& Marlyan M. (2017). Compliments and compliment responses across borders: Language and cultural changes among the new generation of Malays. E Bangi Journal of Social Sciences and Humanities, 12(1), 29-42.

Baddeley, A. D., \& Hitch, G. (1974). Working memory. Psychology of Learning and Motivation, 8, 47-89. https://doi.org/10.1016/S0079-7421(08)60452-1

Bandura, A., Ross, D., \& Ross, S. A. (1963). Vicarious reinforcement and imitative learning. The Journal of Abnormal and Social Psychology, 67(6), 601-607. 
Bruner, J. (1966). Toward a theory of instruction. Harvard University Press.

Carr, V., \& Boat, M. (2019). "You say praise, I say encouragement"--Negotiating positive behavior support in a constructivist preschool. Athens Journal of Education, 6(3), 171-187. https://www.athensjournals.gr/education/2019-6-3-1-Carr.pdf

Cheng, T. F. \& Wu, H. C. (2020). A follow-up study on vocational high school principals' opinions about 360 degree evaluation feedback and their leadership effectiveness and behavior change. Asia Pacific Education Review, 21(1), 65-81.

Coch, D. (2018). Reflections on neuroscience in teacher education. Peabody Journal of Education, 93(3), 309-319.

Dewey, J. (1910). How we think. D.C. Heath \& Co.

Dweck, C. S., \& Yeager, D. S. (2019). Mindsets: A view from two eras. Perspectives on Psychological Science, 14(3), 481-496.

Elizondo-Garcia, J., \& Gallardo, K. (2020). Peer feedback in learner-learner interaction practices. Mixed methods study on an xMOOC. Electronic Journal of e-Learning, 18(2), 122-135.

Finley, T. (2017, November 22). Making sure your praise is effective. Edutopia. Retrieved from https://www.edutopia.org/article/making-sure-your-praise-effective

Frankl, V. (1959). Man's search for meaning. Beacon Press.

Gardner, H. (1987). The mind's new science: A history of the cognitive revolution. Basic Books.

Golato, A. 2005. Compliments and compliment responses: Grammatical structure and sequential organization. John Benjamins.

Hall, S. J. 2018. Plurilingual positioning and its effectiveness in classroom interaction. In

P. Heard (Ed.). Great thinkers. Great minds. Sunway University Professorial Lecture Series (pp. 43-67). Sunway University Press.

Holmes, J. (1986) Compliments and compliment responses in New Zealand English. Journal of Anthropological Linguistics, 28(4), 485-508.

Hofstede, G. (2011). Dimensionalizing cultures: The Hofstede model in context. Online Readings in Psychology and Culture, 2(1), 2307-0919.

Hopwood, C. J., Bleidorn, W., Schwaba, T., \& Chen, S. (2020). Health, environmental, and animal rights motives for vegetarian eating. PloS one, 15(4), e0230609. 
Ishihara, N. (2010) Compliments and responses to compliments: Learning communication in context, In A. Martinez-Flor \& E. Uso-Juan (Eds.), Speech act performance: Theoretical, empirical, and methodological issues (pp. 179-198). John Benjamins.

Jacobs, G. M., \& Farrell, T. S. C. (2001). Paradigm shift: Understanding and implementing change in second language education. TESL-EJ, 5(1). http://www.cc.kyoto-su.ac.jp/information/teslej/ej17/toc.html

Jacobs, G. M., \& Greliche, N. (2017). Convincing students that their groupmates' success can increase, not diminish, their own success. Insight: A Journal of Scholarly Teaching, 12, 145- 157.

Jacobs, G. M., Renandya, W. A., \& Power, M. A. (2016). Simple, powerful strategies for student centered learning. Springer.

Jacobs, G. M., \& Seow, P. (2014, July). Cooperative learning principles enhance online interaction. Paper presented at the global conference on Teaching and Learning with Technology, Singapore. https://www.academia.edu/7590012/Cooperative_Learning_Principles_Enhance_Online_I nteraction and https://files.eric.ed.gov/fulltext/ED573762.pdf

Johnson, D. W., Johnson, R., \& Holubec, E. (2013). Cooperation in the classroom ( $8^{\text {th }}$ ed.). Interaction Book Company.

Kohn, A. (1999). Punished by rewards: The trouble with gold stars, incentive plans, A's, praise, and other bribes. Houghton Mifflin.

Kuhn, T. (1962). The structure of scientific revolutions. University of Chicago Press.

Lee, S. K., Thang, S. M., \& Lee, K. S. (Eds.). (2007). Border crossings: Moving between languages and cultural frameworks. Pelanduk Publications.

Neroni, J., Meijs, C., Gijselaers, H. J., Kirschner, P. A., \& de Groot, R. H. (2019). Learning strategies and academic performance in distance education. Learning and Individual Differences, 73, 1-7.

Piaget, J. (1977). The role of action in the development of thinking. In W. F. Overton, \& J.

M. Gallagher (Eds.,) Knowledge and development (pp. 17-42). Springer.

Piaget, J., \& Inhelder, B. (1962). The psychology of the child. Basic Books.

Pomerantz, A. (1978). Compliment responses. Notes on the co-operation of multiple constraints. In J. Schenkein (Ed.), Studies in the organization of conversational 
interaction (pp. 79-112). Academic Press.

Ryan, R. M., \& Deci, E. L. (2020). Intrinsic and extrinsic motivation from a self-determination theory perspective: Definitions, theory, practices, and future directions. Contemporary Educational Psychology, 101860.

Seligman, M. E. P. (2011). Flourish: A new understanding of happiness and well-being - and how to achieve them. Nicholas Brealey Publishing.

Skinner, B. F. (1953). Science and human behavior. Simon \& Schuster.

Slavin, R. E. (1995). Cooperative learning: Theory, research, and practice ( $2^{\text {nd }}$ ed.). Prentice Hall.

Thilagavathi, S. (2003). The influence of culture on compliment responses. Issues in Language and Cognition. Selected Papers from the Conference on Language and Cognition Faculty of Languages and Linguistics. University of Malaya Press.

Torres, J. O. (2019). Positive impact of utilizing more formative assessment over summative assessment in the EFL/ESL Classroom. Open Journal of Modern Linguistics, 9(1), 1-11.

Valdesolo, P., Shtulman, A., \& Baron, A. S. (2017). Science is awe-some: The emotional antecedents of science learning. Emotion Review, 9(3), 215-221. https://doi.org/10.1177/1754073916673212

Vygotsky, L. (1978). Mind in society: The development of higher psychological processes. Harvard University Press.

Webb, N. M., Franke, M. L., De, T., Chan, A. G., Freund, D., Shein, P., \& Melkonian, D. K. (2009). 'Explain to your partner': Teachers' instructional practices and students' dialogue in small groups. Cambridge Journal of Education, 39(1), 49-70. https://doi.org/10.1080/03057640802701986

Willis, J. (2007). Cooperative learning is a brain turn-on. Middle School Journal, 38(4), 4-13.

Witt, J. K., Linkenauger, S. A., \& Wickens, C. (2016). Action-specific effects in perception and their potential applications. Journal of Applied Research in Memory and Cognition, 5(1), 69-76.

Wolfson, N. (1981). Compliments in cross cultural perspective. TESOL Quarterly, 15(2) 117124. 